\title{
Textbooks 101 A Primer on Writing Your First Book
}

\author{
Steven Barrett, Daniel Pack \\ Department of Electrical and Computer Engineering \\ University of Wyoming, Laramie, WY 82071-3295 \\ e-mail: steveb@uwyo.edu, (307) 766-6181 \\ Department of Electrical Engineering \\ United States Air Force Academy, CO 80840-6236 \\ e-mail: Daniel.Pack@usafa.af.mil, (719) 333-6967
}

\begin{abstract}
This paper presents a guide on the "A, B, Cs" of writing a textbook. Eighteen months ago the authors were novice writers who wanted to publish their first textbook. Their first textbook entitled "The 68HC12 Microcontroller: Theory and Applications," was released by Prentice Hall in December 2001. During the book writing process the authors learned a variety of valuable lessons that they hope are useful to others. This paper presents their thoughts on issues associated with a book writing process: topic and publisher selection, book contracts, time commitments, the actual mechanics of writing, preparing solutions manuals, including software packages, and creating websites.

Although their textbook is intended for an electrical and computer engineering audience, the lessons they learned while writing the book should be applicable to any engineering discipline.
\end{abstract}

\section{Overview}

Several years ago, the authors talked about writing a textbook together in some area of digital design. After all, they had taught, performed research, and consulted in this area for a number of years and were eager to share their knowledge with others. They decided to put talk into action in April 2000 when they began serious planning on writing a book. Both of the authors had published extensively in journals and conference proceedings but neither had written a textbook.

Both authors are full time faculty members. Dr. Pack is a Professor of Electrical Engineering at the United States Air Force Academy, Colorado. Dr. Barrett is an Assistant Professor of Electrical and Computer Engineering at the University of Wyoming. Both authors are typical faculty members with a full teaching load, an active 
research program, and educational related service commitments (committees, advising, etc.). Furthermore, they are both married with children. These details will become important later when they discuss the time commitment required to successfully complete the book in a timely manner.

Two things should be emphasized. First, the authors had no prior experience in writing textbooks and second, they are typical faculty members with typical work and family commitments. If they could write a book, you can too. This paper will guide you through the process of writing a textbook in chronological order. The paper also includes advice from other textbook authors.

\section{Should you consider a co-author?}

There are obvious advantages to having a co-author. Most importantly you can capitalize on each author's strengths. For example, when Drs. Pack and Barrett were in the early stages of book planning they decided that Pack would concentrate primarily on software while Barrett would concentrate on hardware. Furthermore, with a co-author, you have a built-in sounding board for ideas and someone to critically read your first drafts. Pack and Barrett had decided early on that there would be no pride in authorship. Each coauthor was encouraged to critically assess the other's writing. They both understood it was for the overall good of the final product. Aside from a similar philosophy, it is helpful to choose a co-author with a similar work ethic.

In Pack and Barrett's situation, it was a natural choice to work together as co-authors. Pack and Barrett had worked together on a number of projects before the book. Their work relationship was founded on friendship, a deep mutual respect for each others capabilities, and a similar work ethic. Furthermore, they decided early on that they would provide a detailed plan to complete the book and that they would be mutually accountable to one another to meet established deadlines.

\section{Deciding on a Topic}

What should be the topic for a proposed book? It seems the answer is fairly obvious, but the authors had to do some work before answering the question. The first and foremost task for a candidate author is to find a need for writing a textbook. This task can be difficult since whenever a need is identified, you find someone writing and publishing a book to meet that need very quickly.

For the present authors, the task was accomplished rather naturally as a part of their efforts to develop effective and rewarding teaching experiences. As they strove to find methods/tools to make constant improvements to courses by supplementing textbooks with their own materials, they found themselves asking the question: Why not write their own book that addresses all issues that they value? Once they answered this question, the authors were ready to write a book. Of course one must have a thorough knowledge of a subject to identify such needs and to write a book to meet those needs. 
Once the authors decided to write the book, because they believed that they had something to say to educators on how a subject should be taught, they had to ensure that there was not a book that already contained what the authors wanted to say in the book. To this end, a considerable amount of time was spent to carefully review all available books discussing the topic of the book. As a part of the review, the authors identified the difference in the purpose, objectives, and focus of the book with others. By doing so, the authors were able to convince their publisher for the need of the book.

Despite the obvious notion that you must know your audience, a brief comment on the subject is warranted. Once the book topic is determined, one must consider his/her audience for the plain fact that the audience will determine how he/she will present the materials, the level of topic coverage, and supplementary information. Knowing your readers will clearly provide a guide when you start writing your book.

\section{Getting Started}

Once you have decided on a topic the next step is to prepare a prospectus. A prospectus is the package that you provide a potential publisher to obtain a book contract. When you contact potential publishers, they will provide their specific requirements for a prospectus.

Before the prospectus is written the author(s) should carefully consider what the overall, overriding philosophy of the book will be. Pack and Barrett examined some of their favorite textbooks to identify why they liked using them so much. In doing so, a common thread was discovered. The texts had an overriding theme of quality. They discovered each text was carefully written with considerable tutorial information, amply illustrated with figures to illuminate difficult concepts, and provided a "full service" approach to education. These books, in addition to the text, came with a detailed instructor solutions manual, which contained solutions to text problems and laboratory assignments. Sometimes, solutions were also provided to the students on selected homework problems. Finally, where appropriate, a textbook was accompanied with related software. The authors decided to emulate these qualities in their text.

With a philosophy in mind (and written down) detailed work on the prospectus began. The key element of a prospectus is a short, two to three paragraph overview of the book followed by a detailed outline which describes the contents of each chapter to some level of detail.

Pack and Barrett believed that a strong, detailed outline was the key to writing a good book. They spent considerable time deciding on the content of the text, the order that concepts would be covered, examples to be included in each section, and the accompanying laboratory exercises. They worked on their own portion of the outline, combined the portions into a single outline, reviewed the overall product, and then put it aside for awhile. After 7 to 10 days they took a fresh look at the outline, made improvements, and completed a final draft. They provided the draft to colleagues in the computer engineering field and asked them to comment on the outline. They found this was an effective method to obtain an unbiased critique of the outline. The bottom line on 
preparing an outline is the more thought and time provided at this step the better the final product.

In addition to an overview and a strong outline, you may be asked to answer additional questions about your planned work as part of the prospectus. Provided below is the list of additional questions requested by Eric Frank, Acquisitions Editor for Prentice-Hall.

- Outstanding features: What do you consider to be outstanding or unique features of the work?

- Pedagogical features: Will the book include summaries, examples, cases, questions, problems, etc.?

- Supplements: Do you plan to provide supplementary material such as a teacher's manual, study guide, lab manual, solutions manual, software or the like?

- Level: For whom is the book intended and what is the level? What are the student prerequisites, if any? Has the material been class-tested? If not, will it be?

- What is the primary course for which the book is intended? What other courses would it serve?

- Would the work be appropriate for international, technical, or trade markets? What is your expectation of the size of the market? Have you done any market research of your own?

- The Competition - Top three books in the field: How does your book compare and/or contrast with them?

- What schedule of completion do you have in mind for your book?

- What will be the approximate length of your work?

- What kind of art program is needed for you book? What is the estimated number of line drawings and photographs?

- Is the manuscript being prepared on word processing equipment? Describe the equipment you will be using.

- Provide the names and affiliations of qualified reviewers who could be asked to critique the work.

Once the prospectus was complete, it was reviewed, and reviewed again. Remember, this is the primary document you will use to attract a publisher. Again, it is a good idea to ask colleagues in the field to critically review your prospectus.

\section{Time Commitment}

It is important to know exactly how long it will take to complete your book draft. As a part of the contract process, you and your acquisition editor will discuss and come to an agreement on the anticipated book length and the delivery date. When Pack and Barrett developed their prospectus they decided who would write each chapter and when the first draft of each chapter would be available for review by the other co-author. They also agreed on how long each co-author would have to review each other's work. After the critical review of the chapter's first draft, the chapter was returned to the primary author to incorporate the comments. Again, a firm deadline was established for each of these activities. This detailed schedule of milestones allowed each co-author to focus on a single, doable task rather than be overwhelmed by the enormity of completing the book. 
Each co-author also developed their own day-to-day and weekly goals to insure that milestones were met.

Once the actual work began on the book's first draft, how long did it actually take to complete? The textbook the co-authors completed was 10 chapters and approximately 400 pages in length not including appendices. The workload was evenly distributed between the two co-authors. The co-authors began the first draft in June 2000 and mailed it to the publisher on December 15, 2000.

Barrett worked on the textbook every morning before work for 90 minutes and also spent two to three hours per night working on the text. Pack worked on the book on average two to three hours everyday during the first six months. After the first draft was turned in, Pack spent on average 10 hours per week until the book project was complete. This information is provided to help you plan realistic schedules and provide the publisher with an accurate delivery date for the first draft.

\section{Finding a Publisher}

The strategy used by the authors to find a publisher was simple. They sought a company that had an access to a large market and muscle to deliver their product to the market. A number of initial contacts with different publishers were made at technical conferences. The authors knew that those who come to technical conferences have access to university educators who use technical textbooks. The authors soon found out that one of the initial contacts, Prentice Hall, has the largest market share of all engineering textbooks. The choice was easy and the authors have only good things to say about their publisher.

Once the publisher was decided, the book prospectus was sent to the publisher for a review. The initial review was conducted by a multiple individuals from universities and industries. The process took over a month with initial feedback asking the authors to provide additional information. After a few more weeks, the authors heard from the publisher what they were waiting to hear: "Start writing your book!"

\section{The Book Contract}

Along with the approval to write the book, the publisher sent the authors a book contract. In this section, let's consider some of important aspects of a book contract. In most cases, a book contract has a standard format with some blank spaces allocated to fill in specifics. A typical book contract includes agreements on issues associated with items submitted by authors, editing/revision/publishing details, grant of rights, delivery, and royalty.

-Items submitted by authors: A typical contract spells out each item that must be furnished to a publisher by authors. In addition to the book contents, the list includes title page information, table of contents, index, and figures. Authors and a publisher can agree on items such as instructor's manual, a solutions manual, materials for an accompanying web-site, and other supplementary materials. 
-Editing/Revision/Publishing details: The details of who and how your book will be edited, revised, and published are also included in a book contract. Authors generally provide full leeway to a publisher to edit, format, revise, and publish the book as the publisher sees fit with feedback provided by the author(s). Publishers include a clause for authors to revise the contents of a book upon the publisher's request regardless of how authors may feel concerning the change.

-Grant of rights: This particular item of the contract spells out the terms and conditions of rights of the publisher over the work of authors. A publisher's rights include exclusive copyright publication in all languages, reproduction, promotion, and distribution of a book. In general, a publisher will also hold rights to license and broadcast a portion or the entire book in all forms and formats.

-Delivery: The delivery date of the book is specified for authors in the contract. The delivery date is negotiated with the publisher. The present authors' experience is that authors should over-estimate the amount of time required to complete their works to meet the contracted delivery date. A contract specifies a delivery date along with the number of printed book pages that will be delivered to a publisher.

-Royalty: Although receiving the royalty is not the primary motivation of writing a book, it always helps to make sure that you are properly rewarded for your work. A typical royalty ranges from $10 \%$ to $20 \%$ of each book sale. The actual number settled between authors and a publisher depends on the track record of the authors and the projected sales of the book. In addition to a domestic book royalty rate, a typical contract may have separate royalty rates for export sales, direct marketing, and other printed or electronic versions of the book. Finally, authors should make sure that a specified number of books will be furnished to the authors upon publication of the book. (Remember: Your mother will want a copy for her coffee table.)

\section{Writing the Book}

A key decision before beginning actual work on the book is what word processor should be used. Your publisher may require a specific package to render your text. The authors chose to use LATEX because of its capabilities to simply generate many publishing related products. For example, LATEX can be "programmed" to generate a table of contents, list of figures, chapter/section headings, footnotes, and index. Most of these features are specified using one word commands. Also, LATEX allows figures to be seamlessly integrated into the document. Many other word processors have these same features.

It was suggested to the authors by a seasoned textbook writer to place each individual text chapter into separate files. These individual files proved much easier to manage than a large, single cumbersome file. 
As mentioned earlier, the authors followed a plan of primary author write first draft of chapter, co-author critically review first draft, primary author incorporate comments and critiques, and co-author review second draft. This proved to be an effective method of completing each chapter in a timely manner.

Another key decision is whether or not to render your own illustrations. The authors decided to render their own drawings. They felt this was the most effective way of accomplishing text figures. They chose to use Deneba's Canvas SE (Standard Edition) to render figures. Canvas is easy to use and the basic version costs approximately $\$ 119$. Canvas also allows figures to be stored in Encapsulated Postscript Status (EPS). Figures stored in this format were easily imported into LATEX. As with the selection of word processing programs, many other drawing packages have these features.

As previously mentioned, the authors developed a detailed outline with scheduled completion dates of each chapter indicated. They provided this schedule to their acquisition editor. Furthermore, the authors regularly (several times a month) corresponded with their acquisition editor to keep him abreast of their progress. They felt it was important to meet their established deadlines.

The acquisition editor requested three sample chapters two months into the project. The editor provided the chapters to several seasoned technical textbook writers and faculty members who might be using the book in their courses for review. The results from the review were quite devastating. The reviewers indicated that overall the writing and supporting figures were good but the book was written at too high a level. Much more tutorial information was required to reach an acceptable level. It would be easy to say that the authors took the comments in stride and pressed on with the book. Actually, the authors at first took the reviews very personally and quite frankly wondered if they were in "deep water over their heads."

After this initial reaction they realized that this tough review was for the good of the book. With the assistance and guidance of their acquisition editor, they were able to refocus their energy and press on with the remaining chapters of the book. In retrospect, although hard to accept at first, the first external critical review provided a continued impetus to complete a quality product.

The first draft was completed in December 2000 and delivered to the acquisition editor. Both hardcopy and an electronic copy were required. The acquisition editor then provided copies again to external reviewers. The authors did not know the identity of the reviewers. The reviewers provided a detailed critique of each chapter along with suggested improvements for the text. These reviews were provided back to the authors in early March 2001. While the first draft was out for review, the authors worked on solutions for the laboratory exercises and also all homework problems provided at the end of each chapter. These solutions became a 100 page solutions manual.

From March until June 2001, the co-authors worked on the second draft of the textbook incorporating external reviewers' critiques and comments. A second draft was provided 
both to the acquisition editor as well as a production editor. It was the production editor's job to convert the manuscript into a camera ready product suitable for publishing.

The authors received a marked up version of their manuscript from the production editor in late July 2001. The editor had corrected grammar, style, etc. The authors then had the opportunity to review and approve the editor's comments prior to going to the camera ready stage. Once in the camera ready stage, major changes to the manuscript become difficult.

The authors received the camera ready proof of the textbook for review in early September 2001. Again, they were allowed to make only minor revisions during this stage. The final camera ready version was provided to the production editor in midSeptember. The book then went into full-fledged production with an anticipated delivery date of mid-December 2001.

\section{Other considerations}

Once the contents of your book have been written, you must also consider a variety of issues associated with offering your book as a complete package. These issues include writing a solutions/instructor manual, providing a lab manual, offering a student study manual, enclosing a software package, and creating a book website.

For a solutions/instructor manual, one must consider the format, the coverage, and contents of it. Typically, a selected homework problem solutions and comments on how to cover the text materials in a course are included in the manual. We also found the inclusion of figures in a transparency-friendly format in other solution manuals. In many cases one can solicit the help of a competent graduate student to complete the manual.

In engineering and science textbooks, one often finds a set of lab exercises to enhance student learning. Often, a complete coverage of the labs within the textbook may be prohibitive. You may consider writing a separate lab manual to go with your textbook, giving an opportunity for those who desire to perform in-depth laboratory exercises. A student manual is another step to help students maximize their learning. Authors of these manuals give study tips and methods to use the textbook as intended by the authors.

Finding an enclosed software package in engineering textbooks is also common. Such software packages are used along with the textbook to further the learning of students. Typically, the software is used to conduct lab exercises, display complicated results using visual tools, and provide students with opportunities to conduct experiments.

Finally, the website for a book provides additional information related to the contents of the textbook to readers. A website is especially useful if it is periodically updated with up to date information along with links to other valuable, related sites. 


\section{What do other authors have to say}

Several other authors were contacted for their candid advice to first time authors. We tried to strike a balance between seasoned and first time authors from various engineering disciplines. Here is their advice:

Dr. Raymond Jacquot, Ph.D., P.E., Professor Emeritus, Department of Electrical and Computer Engineering, College of Engineering, University of Wyoming, Laramie, Wyoming.

Textbooks: "Introduction to Engineering Systems", R.G. Jacquot and F.M. Long, and "Modern Digital Control Systems", R.G. Jacquot.

Comments: "Here are a few of my observations in reference to textbook authoring:

- Best to wait until you get tenure. Prior to that, time should be spent on other more rewarding scholarly efforts e.g. proposals and journal articles.

- The great co-author trap.--I've seen too many people team with a co-author who, in the end, will not produce their share of the project. This leaves two alternatives:

- Abandon the textbook project.

- Do it all yourself--then do you keep the non-producer as a co-author? How do you shed them without going to court?

- Cover art-- Include in the contract that you must approve any art selected for the cover. Sometimes an editor will select a figure that is, at best, peripheral to the topic of the text".

Dr. John D. Enderle, Ph.D., Professor, Program Director for Biomedical Engineering, Co-Editor, EMB Magazine, University of Connecticut.

Textbooks: Enderle, J.D., Blanchard, S.M., and Bronzino, J.D., Introduction to Biomedical Engineering. Academic Press, San Diego, California, 2000, 1062 pages.

Enderle, J.D. and Hallowell, B. (Editors), National Science Foundation 1999 Engineering Senior Design Projects to Aid Persons with Disabilities. Creative Learning Press, Inc., Mansfield Center, Connecticut, 2001, 360 pages. (Available for viewing at: http://nsf-pad.bme.uconn.edu). There are also 10 other books in this series dating back to 1989 .

\section{Comments:}

- "The time spent on writing a book is much longer than you ever anticipate. This makes the financial return on writing a book about 1 penny an hour spent writing!

- Despite your best efforts, errors will be printed either committed by the author or the publisher. I have a website for the "Introduction to Biomedical Engineering" book that posts an errata sheet; this makes it easier to live with the mistakes.

- I have another book that I started in 1985 with two other co-authors (Applied Probability and Random Processes for Electrical Engineers). We made great 
progress on the beginning of the book, but ran out of energy before writing the last three chapters. Interestingly, one of the co-authors retired and last summer the two remaining co-authors discussed finishing the book this academic year! I must say that I had a great deal of fun working with the two other co-authors and found the experience to be very rewarding and worthwhile, even if it never gets published.

- I started working on the NSF book series alone in 1988. Each book required a tremendous amount of rewriting and work. Beginning with the 1996 Edition, Brooke Hallowell became the Co-Editor of the book series, which made publishing the book much easier and fun. Brooke is a delight to work with and has become a great friend!

- I am writing my first solo textbook now (Physiological Modeling: An Introduction for Biomedical Engineers). This book has been much easier to write, but not as much fun as working with my other co-authors. I truly miss working with Susan Blanchard on this project, a most perfect a co-author that one could ever find."

Dr. Mitchell A. Thorton, Ph.D., P.E., Mississippi State University, Starkville, MS

Textbook: "Spectral Techniques in VLSI CAD”, Mitchell A. Thornton, Rolf Drechsler, D. Michael Miller, Kluwer Academic Publishers, Boston, MA, ISBN 0-7923-7433-9, July 2001

Comments: "Several things should be considered before the actual writing of the textbook proceeds. Particularly in the case of multi-author books all mathematical notation should be decided upon ahead of time for consistency, the software to be used for word processing and figure drawing should be agreed upon and it is highly recommended that authors use the same software packages for interoperability and consistency. Other issues are the placement of captions with regard to figures and tables, the amount of nesting in the index and an approximate number of words per chapter to include in the index. After these details have been agreed upon, actual writing can begin.

A method for ensuring concurrent generation of text is to assign primary responsibility of a subset of chapters to each author. After the primary author has written the chapter she/he is responsible for, it can then be passed along to the other authors. Version control is extremely important and if careful measures are not taken keeping the latest updates in the book draft can become a nightmare. One solution is to use version control software such as CVS. Although these systems were originally developed for teams of programmers working on large computer programs, they are perfectly suited for this purpose as well and allow for previous versions to be recalled and for locking out portions of the draft that are currently being edited by another author".

\section{Celebration}

Once the galley proofs are mailed in, only waiting for the actual book is left. The authors shipped in the galley proofs in mid-September and the book came out in mid-December. Seeing and holding your first book in the flesh can be an overwhelming experience. You 
forget all the late nights, numerous proof readings, and correction iterations that went with the book writing process but enjoy the accomplishment in the "flesh."

\section{Conclusion}

In this paper the authors have candidly taken you through their experiences and lessons learned while writing their first textbook. They found this to be a very challenging and rewarding experience. All things considered, would the authors do it again? They are currently working with the same publisher on their second textbook.

Steven F. Barrett received the BS Electronic Engineering Technology from the University of Nebraska at Omaha in 1979, the M.E.E.E. from the University of Idaho at Moscow in 1986, and the Ph.D. from The University of Texas at Austin in 1993. He was formally with the United States Air Force Academy, Colorado and is now an Assistant Professor of Electrical Engineering, University of Wyoming. He is a member of IEEE (senior), Tau Beta Pi, and serves as the President, Rocky Mountain Bioengineering Symposium, Inc. His research interests include digital and analog image processing, computer-assisted laser surgery, and embedded controller systems. He is a registered Professional Engineer in Colorado.

Daniel Pack is a Professor in the Department of Electrical Engineering at the United Air Force Academy, CO. He received the Bachelor of Science degree in Electrical Engineering in 1988, the Master of Science degree in Engineering Sciences in 1990, and the Ph. D. degree in Electrical Engineering in 1995 from Arizona State University, Harvard University, and Purdue University, respectively. He is a member of Eta Kappa Nu, Tau Beta Pi, IEEE, and ASEE. He is a registered Professional Engineer in Colorado. His research interests include intelligent control, automatic target recognition, robot vision, and walking robots. 